\title{
DOI 10.26886/2414-634X.1(45)2021.1
}

UDC: 331.108

\section{FEATURES OF PERSONNEL DEVELOPMENT IN TERMS OF} INNOVATIVE CHANGES

\author{
F. A. Babayev, Postgraduate student \\ e-mail: kafedrahrmanagement@gmail.com \\ PJSC "Higher Educational Institution "Interregional Academy of Personnel \\ Management", Ukraine, Kyiv
}

The article is devoted to the analysis of the theoretical aspects of personnel development. The purpose of the article is to identify the features of personnel development in terms of innovative changes. The essence of the concept of "personnel development" was considered, its role in improving the competitiveness of personnel and the enterprise as a whole in the context of innovative changes was revealed. The analysis of the most successful practices of personnel development in the context of innovative changes is carried out on the examples of leading corporations in Japan and the USA. The conditions for the development of personnel are determined. It's the formation of innovation-oriented personnel, an innovative corporate culture, a highly qualified team, stimulating growth and expanding the competence of employees. The main directions for improving of personnel development in terms of competition and innovative changes are proposed.

Key words: personnel development, innovation-oriented personnel, competent personnel, foreign experience in personnel development, development conditions.

аспирант, Бабаев Ф. А. Особенности развития персонала в условиях инновационных изменений / ЧАО «ВУЗ «Межрегиональная Академия управления персоналом», Украина, Киев 
В статье проведен анализ теоретических аспектов развития персонала. Целью статьи является выявление особенностей развития персонала в условиях инновационных изменений. Рассмотрена сущность понятия «развитие персонала», его роль для повышения конкурентоспособности персонала и предприятия $в$ целом в условиях инновационных изменений. Проведен анализ наиболее успешных практик развития персонала в условиях инновационных изменений на примерах передовых корпораций Японии и США. Определены условия развития персонала: фрормирования инновационно ориентированного персонала, инновационной корпоративной культуры, высококвалифицированного коллектива, стимулирования роста и расширения компетентности сотрудников. Предложены основные направления совершенствования развития персонала в условиях конкуренции и инновационных изменений.

Ключевые слова: развитие персонала, инновационно ориентированный персонал, компетентный персонал, зарубежный опыт развития персонала, условия развития.

Введение. Развитие экономики любой страны невозможно без участия в системе мирохозяйственных связей и инновационных изменений. Как следствие, усиливается конкуренция за счет проникновения на национальный рынок конкурирующих предприятий из-за границы, а расширение производства и диверсификации рисков диктует необходимость выхода на рынки других стран. Проникновения на зарубежные рынки, которые привлекают огромными торговыми оборотами, требует соблюдения высоких требований к качеству продукции и стиля ведения бизнеса. 
Активное, с выгодой для Украины, участие в евроинтеграционных процессах, возможна только при условии развития человеческих ресурсов, задействованных в экономике. Специфической чертой современности является мощное распространение научнотехнического прогресса на всех континентах с появлением большого количества социально-экономических связей, новаций в области техники, технологии, цифровизации и др. Считаем, что украинские предприятия могут стать конкурентоспособными на внешних рынках за счет выпуска инновационной продукции и предоставления высокотехнологичных услуг. Отвечать этим требованиям возможно при наличии квалифицированных управленческих и исполнительских кадров. В условиях современной динамичной глобализации экономики, успех в которой обусловлен использованием интеллектуального капитала, обеспечить конкурентоспособность отечественной рабочей силы может современный подход к развитию персонала.

Анализ последних исследований и публикаций. Научные разработки концепции человеческого капитала отражены в трудах ученых в области менеджмента, управления персоналом, педагогики, психологии, что обуславливает различные подходы к трактовке самого понятия «развитие персонала» и, соответственно, обозначило широкий спектр факторов и направлений активизации этого процесса. Вопросы развития персонала с точки зрения повышения эфффективности деятельности организации рассматривали ученые в области управления персоналом (HR-management): Веснин В.Р., Данюк В. М., Дмитренко Г. А., Кибанов А. Я., Крушельницкая О. В., Котвицкий А. А., Петюх В.Н., Цимбалюк С. А., Червинская Т.М. и другие, которые понимают развитие персонала как процесс, направленный на приобретение работниками необходимых для выполнения функциональных обязанностей компетентностей, 
повышает уровень конкурентоспособности работников на рынке труда. В трудах ученых Анисимова О. С., Деркача А. А., Зазыкина В.Г., Маркова А.К., Колпакова В.М., Щекина Г.В. вопросы развития персонала рассматриваются с позиции создания условий для развертывания имеющихся интеллектуальных, творческих, фризических резервов личностей в процессе их жизнедеятельности и трудовой деятельности. Степень реализации резервов зависит от соответствия управленческого воздействия наследственным программам, социальным условиям, а также от степени благоприятности условий для самореализации и развития на предприятии. Однако при всей значимости указанных исследований, в них в основном сосредоточено внимание на деятельности кадровых служб по организации обучения сотрудников, что в современных условиях является лишь одним из направлений развития персонала.

Формулировка цели статьи и задач. Целью данной статьи является выявление особенностей развития персонала в условиях инновационных изменений.

Задачи исследования: конкретизация сущности понятия «развитие персонала», а также определение основных направлений совершенствования развития персонала в условиях конкуренции и инновационных изменений.

Изложение основного материала исследования. В современных условиях в рыночной среде, стремительно обострились, идет буквально жесткая конкурентная борьба за выживание, работать приходится по-новому; топ-менеджмент и владельцы бизнеса предъявляют много новых условий для наемного персонала, который должен гибко реагировать на рыночный спрос, формировать и расширять клиентскую базу, владеть средствами оперативноадаптивного реагирования на изменения в производственных 
процессах и функциональных обязанностях, быть стрессоустойчивым, мобильным, неравнодушным и тому подобное. Таким образом, ситуация требует от каждого работника постоянного развития профрессиональных и личных качеств [1, с.33-34]. Во всем этом множестве связей, инноваций и их применении в различных сферах хозяйствования ключевую роль играет, безусловно, человек. И не только как главная производительная сила общества, что осуществляет изобретения и обеспечивает их использование, но и как личность, которая имеет свой интеллект, темперамент, черты характера, способности, различные качества и свойства. Это во многом обусловливает поведение человека $и$ влияет на всю деятельность, в частности на ее инновационный характер. Существенно влияет это (из-за качества управленческой элиты) также на формирование всего цивилизационного направления развития обществ, которое в последние десятилетия все больше, к сожалению, ошибается в сторону бездуховного эгоцентризма с исключительно приоритетами материального достатка.

Рассмотрение теоретических аспектов по развитию персонала имеет важное значение для проведения анализа развития и обучения персонала В конкретной организации. В научных кругах идут противоречивые дискуссии о понятии «развитие персонала». По мнению Колпакова В.М., причиной различий в определении понятия «развитие персонала» можно объяснить некорректным использованием в практической деятельности таких понятий как «обучение», «образование», «воспитание». Под образованием понимают процесс педагогически организованной социализации, осуществляемой в интересах личности и общества, или освоение культурного наследия общества и связанного с ним уровня индивидуального развития, под обучением - совместную деятельность 
учителя и ученика по познанию явлений окружающего мира, их закономерностей, историю развития и освоение способов деятельности .... Воспитание - это целостное влияние, цель которого в накоплении ребенком необходимого для жизни в обществе социального опыта и формирования у него системы ценностей. Обучение отличается от воспитания организованностью [2, с.65].

Современную проблематику развития персонала активно исследуют и обсуждают многочисленные ученые. Так, одни авторы трактуют понятие «развитие» как специфический процесс, который происходит при реализации определенного набора действий с учетом поставленных целей [3, с. 237]. Другие объясняют развитие как комплексный и непрерывный процесс с целью повышения эфрфективности работы [4, с.148].

Развитие персонала также рассматривается как целенаправленный комплекс информационных, образовательных видов деятельности, привязанных к требованиям конкретных должностей, их элементов, которые способствуют повышению квалификации работников определенного предприятия в соответствии с задачами развития самого предприятия и потенциала (способностей) сотрудников [5, с. 309].

Более подробно это понятие рассматривает А. Кибанов, который утверждает, что «развитие персонала» - это совокупность организационно-экономических мероприятий службы управления персоналом в сорере обучение персонала, организации его переподготовки и повышения квалификации [6, с. 85]. Эти мероприятия касаются вопросов профессиональной адаптации, оценки кандидатов на вакантную должность, текущей периодической оценки кадров, планирования деловой карьеры и служебнопрофессионального продвижения, работы с кадровым резервом. 
Однако, на наш взгляд, не целесообразно ограничивать «развитие персонала» лишь мероприятиями кадровых служб. Сегодня очень большое внимание уделяется как раз саморазвитию. Таким образом, развитие персонала - это совокупность взаимосвязанных мероприятий, направленных на расширение компетентности, приобретение новых знаний, умений, навыков, опыта в процессе обучения, повышения квалификации, переподготовки с целью адаптации к новым условиям деятельности, обеспечение собственных интересов развития и реализации целей деятельности предприятия.

Понятие развития и обучения тесно связаны между собой. Если обучение представляет собой процесс непосредственно передачи новых профрессиональных знаний или навыков сотрудникам организации и нацелено на развитие способностей для выполнения работником соответствующих функций, то развитие направлено на фрормирование среды для самосовершенствования, повышения мастерства работников с тем, чтобы они могли продвигаться по службе и эфффективно решать будущие задания. Развитие представляет собой процесс подготовки сотрудника фрирмы к выполнению новых производственных функций, занятия новых должностей, решению новых задач. В свою очередь, развитие персонала традиционно базируется на организационных учебных процессах, которые управляются и фринансируются тем предприятием, для которого эти процессы предназначены. Следовательно, обучение персонала является основой его развития для любой организации. Мерами по профессиональному развитию, например, могут быть семинары по маркетингу для сотрудников отдела кадров, изучение иностранного языка инженером-механиком и т.д. [2, с.23].

В современных условиях именно развитие персонала выступает одним из весомых фракторов конкурентоспособности предприятия. 
Высокий уровень профессиональной компетентности, мотивация к обучению и стремление работников к самообучению и самореализации срормируют соответствующий уровень конкурентоспособности персонала. Квалифицированный работник характеризуется большей мобильностью на рынке труда и более конкурентоспособен.

Мировая практика хозяйствования знает много случаев творческого и системного подхода к решению актуальных вопросов развития персонала и значительных достижений в этой области. В развитых странах Европы, Северной Америки и Восточной Азии этими вопросами последовательно $и$ настойчиво занимаются ученые $и$ практики по меньшей мере со времен известного ученого Ф. Тейлора.

Украина, к сожалению, такого длительного опыта в сфере развития персонала не имеет. Более или менее успешные предприятия начали осваивать эту проблематику с переходом к рыночной экономике с 90-х годов. Именно в этот период была примитивная советская практика подготовки кадров. О системном и непрерывном развитии персонала тогда речь вообще не шла, но баланс между потребностями экономики в рабочих кадрах и их подготовкой в системе профтехобразования и специалистов в вузах кое-как поддерживался.

За предыдущие 2-3 десятилетия в мире много написано и сказано о важности и ценности развития персонала. Крупные и успешные предприятия имеют значительные достижения в этом деле. Например, опрошенные 1200 менеджеров крупных и средних японских предприятий $85,3 \%$ утверждали, что наибольшего внимания руководителей требует развитие человеческих ресурсов. Для сравнения: новая технология была названа шестой по порядку $(44,4$ \%). Полученные результаты исследований в ряде американских фрирм 
показало, что на 83\% из них службы человеческих ресурсов занимаются развитием персонала, в большинстве таких предприятий создан специальный сектор обучения [7, с. 81-82]. Во время пребывания Тома Уотсона на посту президента (50-е и 60-е годы) в ИВМ было две актуальные обязанности, а именно: уделять 25\% рабочего времени работников обучению и стремиться к полной реализации потенциала каждого сотрудника [7, с.78].

Если в администрации предприятия или в ффункциональных подразделениях готовят какие-то изменения в технологии, организации производства, информационном обеспечении и т.п., то соответствующая документация сначала как проект для обсуждения проходит через все заинтересованные службы, через все степени управленческой иерархии вплоть до непосредственных исполнителей. Каждый, кто берется за какое-то конкретное дело, должен внимательно изучить его, высказать свое мнение, дать свою оценку, сформулировать свои предложения.

Так в условиях инновационных изменений уникальную стратегию развития работников создали и успешно реализуют в американской ИТ-компании Next Jump (которая специализируется на интернетпродажах). Предприятие сформировало огромный рынок, в котором объединило около 30 тысяч торговых единиц с 70 миллионов сотрудников из 4000 крупных компаний и 100 тысяч представителей малого бизнеса. Таким образом, объем ежегодных продаж исчисляется миллиардами долларов [8, с. 26]. Эта уникальная стратегия по своей основной сути есть системой осознанного саморазвития личности каждого работника в процессе работы при активной помощи руководителей и его сотрудников [8, с. 11].

По нашему убеждению, главное назначение системы саморазвития личности каждого работника заключается в том, чтобы 
освободить его от ложных представлений о себе, полностью раскрыть его потенциал, стимулировать его к постоянному саморазвитию в процессе работы и всячески помогать ему в этом. Кроме компании Next Jump на такой путь осознанного саморазвития работников стали еще такие две крупные корпорации, как Bridgewater Associates и Decurion.

Создание и развитие этой системы во всех трех корпорациях - это непрерывный процесс основной деятельности трудового коллектива и одновременного совершенствования всех работников от высшего руководства до самых низких должностей и новичков. Обе части этого процесса являются равнозначными и взаимозависимыми. В Next Jump «под время регулярного пересмотра зарплат вклад каждого работника в производство оценивается в 50\%, его же вклад в общую корпоративную культуру - 50\% [8, с. 33].

В процессе многолетней практики корпорациями наработанный комплекс эффрективных мер по постоянному развитию человеческого потенциала. Первым и очень важным мероприятием является тщательный отбор специалистов на вакантные должности среди наиболее конкурентоспособных и мотивированных выпускников колледжей и университетов. Далее, в условиях инновационных изменений специалисты Next Jump, в том числе и те, которых перевели на руководящие должности, первые три недели проходят обучение в Учебном лагере саморазвития.

В Учебном лагере новички работают с клиентами, а менеджеры тем временем помогают новичкам осознавать свои различные недостатки и слабости, от которых они постепенно избавляться.

В компании Bridgewater существует документ под названием «Принципы», который ориентирует персонал укреплять и поддерживать культуру полной честности и прозрачности. 
Каждый работник обязан отмечать свои и чужие ошибки в специально созданном информационном массиве под названием «Журнал проблем». ошибки и нерезультативные действия следует записывать очень подробно, это поощряется. Это не каталог позорных ошибок как основание для освобождения или лишения бонуса, это полезное пособие, с которого коллеги черпают важные знания и становятся лучше. Если работник этого не делает, то это расценивается как существенное нарушение должностных обязанностей.

Другой способ убедить работников в том, что надо признавать и обдумывать свои ошибки - ведение дневника собственных переживаний, связанных с работой. В приложении «Кнопка боли» люди откровенно делятся своими негативными переживаниями. Эти записи обсуждаются в атмосфрере доброжелательности и желания помочь друг другу в самосовершенствовании [8, с. 108].

Основные направлениями совершенствования развития персонала в условиях конкуренции и инновационных изменений представлены на рис.1.

Условиями развития персонала является организация и обеспечение процесса образования, целенаправленной подготовки, осуществляется посредством обучения, воспитания, тренировки, социализации, приобретения опыта, которые должны быть составляющими современных моделей развития персонала на предприятиях.

Личностное развитие персонала главным образом зависит не только от эффрективно построенной образовательной программы, но и от наличия у него определенных личностных качеств, которые будут влиять на успешность его развития, а также направленности интересов, мотивации [11, с.39]. В то же время необходимо 


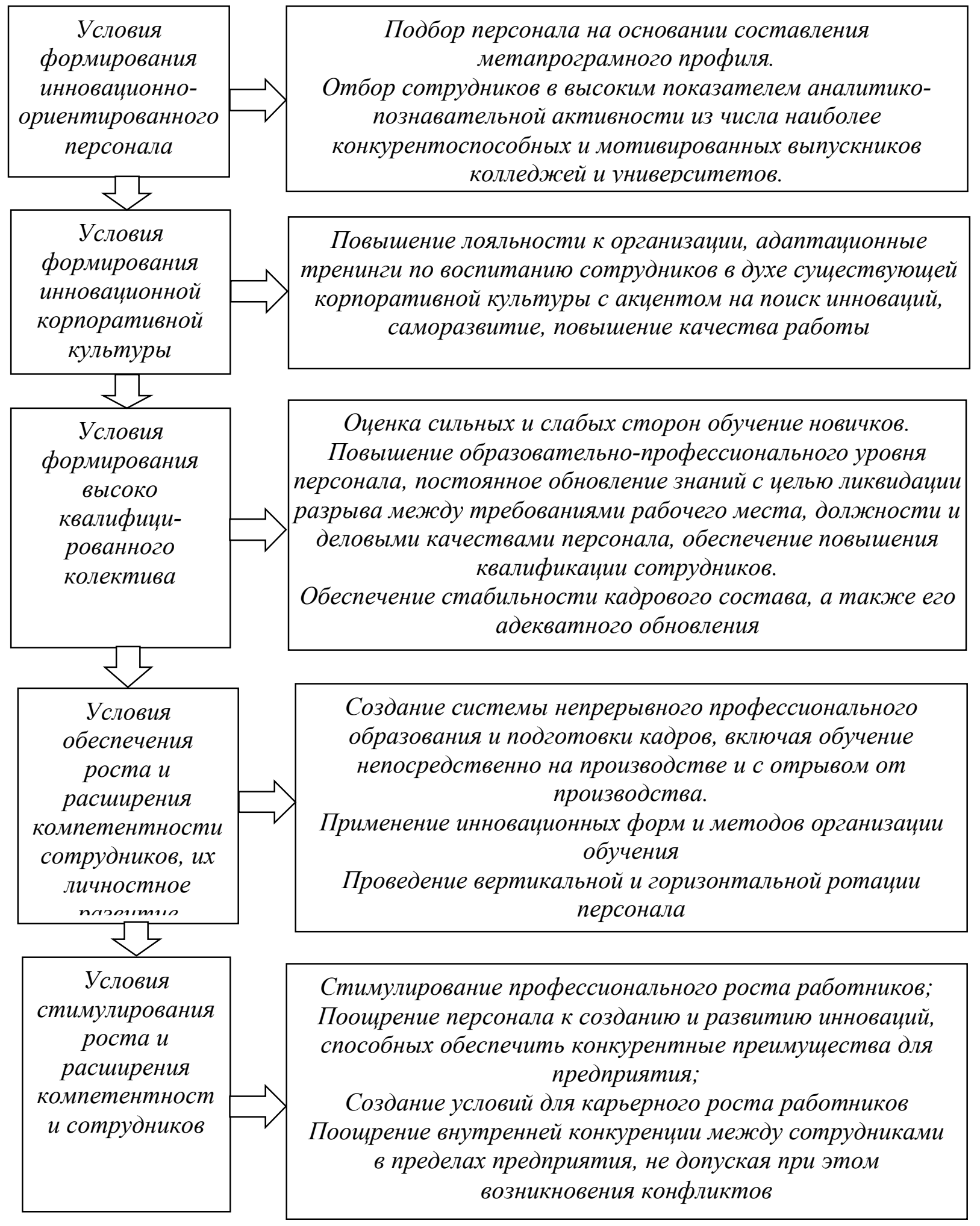

Рис.1. Основные направления совершенствования развития персонала в условиях конкуренции и инновационных изменений

Источник: разработано автором на основании [2, 9]. 
сорормировать условия для инновационной деятельности, ведь без этого, даже если на предприятии есть новаторы, инновации не смогут быть воплощены в практику хозяйствования, а потому будет невозможно обеспечить «конкурентоспособный эффект» отдельной организации, а затем и экономики в целом. Значит, нужны определенные условия, в том числе и мотивационные, чтобы изобретательские способности и склонность к инновационной деятельности людей были использованы с пользой для самого человека и для общества [4].

Выводы. Развитие персонала в современных условиях является основным фрактором конкурентоспособности, который обеспечивает долгосрочное процветание предприятия. Для сотрудников оно обеспечивает профессиональный, интеллектуальный, нравственный, личностный рост, раскрывая их потенциал. Для предприятия - это динамичный, четко спланированный, перманентный процесс необходимый для достижения стратегических и оперативных целей организации, с помощью технологий обучения, повышения квалификации, управление карьерой, социального и личностного развития, управления трудовой мотивацией и стимулированием персонала и тому подобное.

Основными направлениями совершенствования развития персонала считают повышение образовательного уровня работников, поощрение инноваций, фрормирования системы непрерывного профрессионального образования и подготовки кадров, включая повышение квалификации, применение инновационных форм и методов организации обучения, создание условий для карьерного роста работников, поощрение внутренней конкуренции.

\section{Лumepamypa:}


1. Згалат-Лозинська Л.О. (2019). Методологічні та соціальнотехнологічні засади інноваційної діяльності організацій: людиноцентричний контекст. Причорноморські економічні студії. Вип. 48-3. C.27-34. DOI: https://doi.org/10.32843/bses.48-69

2. Колпаков В.М. (2006). Управление развитием персонала: Учеб. пособие для студентов вузов. К. МАУП. 712 с.

3. Савченко В.А. (2015). Розвиток персоналу: підручник. 2-ге вид., перероб. і доп. Київ. КНЕУ. 505 с.

4. Данюк В. М., Петюх В.М., Цимбалюк С.О. (2006). Менеджмент персоналу: Навч. посіб. за заг. ред. В. М. Данюка, В. М. Петюха. Київ. KHEY. 398 c.

5. Веснин В.Р. (2001). Практический менеджмент персонала: пособие по кадровой работе. В.Р. Веснин. Москва: Юристъ. 496 с.

6. Управление персоналом организации (2005). учебник. Под ред. А.Я. Кибанова. 3-е изд., доп. и перераб. М. ИНФРА-М. 638 с.

7. Панченко Є.Г. (2010) Дослідний університет: Гарвардські принципи. Вища освіта: шляхи розвитку та забезпечення якості. Київ. КНЕУ. С. 77-107.

8. Культура для каждого. Как стать организацией осознанного развития. (2017). Р. Киган и др.; пер. с англ. М. Попова; [науч. ред. Е. Пустошкин]. Москва. Манн, Иванов и Фербер. 320 с.

9. Holovach N., Bakhov I., Zgalat-Lozynska L. (2019). An Innovation-Driven Model for Management Personnel Development at Enterprises. Jour of Adv Research in Dynamical \& Control Systems, vol. 11, 12-Special Issue, pp.1266-1277. DOI: 10.5373/JARDCS/V11SP12/20193335

10. Системна модернізація державного управління в Україні: кол. монографрія. (2020). За заг. ред. Г.А. Дмитренка. К. ДСК-Центр. С. 73149. ISBN 978-617-7300-55-6

11. Кочемировська О. О. (2014). Розвиток трудового потенціалу як 
чинник економічного зростання України: аналіт. доп. О.О. Кочемировська. Київ: НІСД. 108 с.

\section{References:}

1. Zghalat-Lozynska, L.O. (2019). Metodolohichni ta sotsialnotekhnolohichni zasady innovatsiinoi diialnosti orhanizatsii: liudynotsentrychnyi kontekst [Methodological and socio-technological principles of innovation of organizations: human-centered context]. Black Sea Economic Studies, vol. 3, no. 48, pp. 27-34. DOI: https://doi.org/10.32843/bses.48-69

2. Kolpakov, V.M. (2006). Upravlenye razvytyem personala [Management of personnel development], Kyiv, MAUP [in Russian]

3. Savchenko, V.A. (2015). Rozvytok personalu [Staff development: textbook], Kyiv: KNEU [in Ukrainian].

4. Daniuk, V. M., Petiukh, V.M. Tsymbaliuk S.O. (2006) Menedzhment personalu [Personnel management], Kyiv. KNEU [in Ukrainian]

5. Vesnin V.R. (2001) Prakticheskiy menedzhment personala: posobie po kadrovoy rabote [Practical personnel management: a manual for personnel work]. Moscow: Yurist. [in Russian]

6. Kibanov A.Ya. (2005) Upravlenie personalom organizatsii [Organization personnel management]. Moscow: INFRA-M. [in Russian]

7. Panchenko E.G. (2010). Doslidnyy universytet: Harvards'ki pryntsypy. Vyshcha osvita: shlyakhy rozvytku ta zabezpechennya yakosti [Experimental University: Harvard Principles. Higher education: ways of development and quality assurance], Kyiv [in Ukrainian]

8. Kegan R. (2017). Kul'tura dlja kazhdogo. Kak stat' organizaciej osoznannogo razvitija [Culture for everyone. How to become an organization of informed development]. Moscow. [in Russian].

9. Holovach N., Bakhov I., Zgalat-Lozynska L. (2019). An Innovation-Driven Model for Management Personnel Development at Enterprises. Jour of Adv 
Research in Dynamical \& Control Systems, vol. 11, 12-Special Issue, pp.1266-1277. DOI: 10.5373/JARDCS/V11SP12/20193335

10. Dmytrenko H.A. (2020) Systemna modernizatsiia derzhavnoho upravlinnia $v$ Ukraini [System modernization of public administration in Ukraine]. Kyiv: DSK-Center [in Ukrainian] ISBN 978-617-7300-55-6

11. Kochemirovskaya O.O. (2014). Rozvytok trudovoho potentsialu yak chynnyk ekonomichnoho zrostannya Ukrayiny: analit. dop. [Development of labor potential as a factor of Ukraine's economic growth: analyst. inf.], Kyiv. NISD. [in Ukrainian].

Citation: F.A. Babayev (2021). FEATURES OF PERSONNEL DEVELOPMENT IN TERMS OF INNOVATIVE CHANGES. New York. TK Meganom LLC. Innovative Solutions in Modern Science. 1(45). doi: 10.26886/2414-634X.1(45)2021.1

Copyright: F.A. Babayev (․ 2021. This is an openaccess article distributed under the terms of the Creative Commons Attribution License (CC BY). The use, distribution or reproduction in other forums is permitted, provided the original author(s) or licensor are credited and that the original publication in this journal is cited, in accordance with accepted academic practice. No use, distribution or reproduction is permitted which does not comply with these terms. 